\title{
PERITONEAL DIALYSIS FOR HEART FAILURE
}

\author{
Harish Puttagunta ${ }^{1}$ and Stephen G. Holt ${ }^{1,2}$ \\ Royal Melbourne Hospital, ${ }^{1}$ and The University of Melbourne, ${ }^{2}$ Melbourne, Australia
}

\begin{abstract}
Heart failure (HF) is a common and important cause of morbidity and mortality in the elderly, imposing a significant burden on healthcare systems. Better management of ischemic heart disease has resulted in increased survival and growth in the number of prevalent heart failure patients, but co-existing renal impairment complicates management and limits traditional therapeutic options. Ultrafiltration (UF) techniques have shown promise in the treatment of diuretic-resistant HF, but the early successes of extracorporeal treatments has not been confirmed by randomized trials. Peritoneal dialysis (PD) may be cheaper and provide more effective UF therapy in selected patients and this review examines the issues surrounding the use of PD for such patients. Whist many nephrologists are enthusiastic about the use of this technique, making a more cogent case for PD in this setting for cardiologists is likely to need a combined strategy of demonstrating improvement in individual cases and further study of potential medicoeconomic benefits.
\end{abstract}

Perit Dial Int 2015; 35(6):645-649

http://dx.doi.org/10.3747/pdi.2014.00340

KEY WORDS: Peritoneal dialysis; elderly; heart failure; ultrafiltration; cardiorenal.

A round a third of patients reaching end-stage renal failure have heart failure (HF) at start of dialysis (1), with the highest incidence and prevalence in the elderly, this diagnosis being the most frequent cause of hospital admission and readmission in some parts of the world (2). Whilst this may be partly explained by increasing survival in patients with ischemic heart disease, advances in HF management may have started to make inroads into the secondary and tertiary care burden of this condition, as admission rates may have plateaued or started to decline recently (3). Overall mortality rates after hospitalization for HF remain stubbornly high, with a riskadjusted 1-year mortality rate of around $30 \%$ (3). The costs of treating HF remain enormous, estimated in 2010 to be in excess of $\$ 39$ billion in the US alone (4). Heart failure and chronic kidney disease (CKD) frequently co-exist and the presence of CKD confers a doubling of the risk of all-cause mortality.

Correspondence to: Stephen G. Holt, Director of Nephrology and Consultant Nephrologist, Dept of Nephrology, Royal Melbourne Hospital, Grattan Street, Parkville, Australia.

steve.holt@mh.org.au

Received 29 December 2014; accepted 26 July 2015.
Indeed, elderly patients with CKD have a higher chance of dying from a cardiovascular cause than starting dialysis (5). However, whether renal dysfunction induces cardiovascular abnormalities or vice-versa or both is far from clear in many patients, and there is good evidence for bidirectional causality (6), with one system dysfunction predating the other, leading to a newer classification of cardio-renal syndromes (CRS), where a number of the following scenarios are represented: acute CRS (acute impairment in cardiac function causing renal dysfunction), chronic CRS (chronic cardiac dysfunction causing renal dysfunction), acute reno-cardiac syndrome (RCS) (acute decline in kidney function causing cardiac dysfunction), and chronic RCS (chronic kidney disease causing cardiac dysfunction). Traditionally, these groups have been lumped into a single CRS diagnostic group, which may have limited or confounded previous studies (7). Mechanisms involved in myocardial and vascular decline in renal disease include aldosterone-induced cardiac fibrosis, atherosclerosis, vascular stiffening, left ventricular hypertrophy (LVH), and medial vascular calcification consequent upon mineral bone disturbance and associated proteins (e.g. PTH, FGF23, klotho, Fetuin-A, Matrix GLA protein, osteoprotegerin and RANK-L amongst others).

\section{HEART FAILURE TREATMENTS}

The treatment of HF traditionally starts with nonpharmacological measures like salt and fluid restriction, smoking cessation, and weight loss as well as the use of diuretics, angiotensin converting enzyme inhibitors (ACEI), or angiotensin receptor blockers (ARB), vasodilators and betablockers. Whilst many patients respond to such strategies, a number of patients are resistant or intolerant of some or all of these therapies (8). Furthermore, many patients with $\mathrm{HF}$ have co-existent or develop worsening renal dysfunction and newer therapies have been proposed (including recombinant B-type natriuretic peptide [BNP], relaxin analogues, vasopressin $\mathrm{V}_{2}$-receptor and adenosine $\mathrm{A}_{1}$-receptor antagonists). Occasionally, more aggressive approaches are adopted, including intravenous inotropes, cardiac resynchronization with dual chamber pacing, mechanical circulatory support, and continuous positive airway pressure. Cardiac transplantation is rarely offered over 65 years but significant renal dysfunction is almost always a contraindication to this. There is also an increasing recognition that, in certain individuals, this diagnosis may be 
one best looked after by symptom control and conservative care pathways leading to end-of-life care (9).

However, as nephrologists, we have long recognized the ability to optimize cardiac function by adjusting blood volume and reducing edema, predominantly by removal of excess salt and water by ultrafiltration (UF). Peritoneal dialysis (PD) has been promulgated as a therapeutic intervention for heart failure since 1949 (10) but we have largely failed to get cardiologists interested in the technique until recently. Mechanisms of sodium and water removal include various extracorporeal blood circuits or PD-based methods. Most UF therapies for heart failure advocate slow removal of water and solute allowing adequate time for vascular refilling from extravascular spaces thereby avoiding hypotension in patients with vulnerable hemodynamics. Potentially other useful side effects of such therapy might include enhanced potassium removal which may allow reinstitution of an ACEI/ARB or aldosterone antagonist (e.g. spironolactone) which have proven mortality benefits in $\mathrm{HF}$ (8). A reduction in diuretic dose may also be desirable, as higher doses may lead to intravascular volume depletion and worsening of renal dysfunction and have been implicated in mortality in heart failure (11).

\section{ULTRAFILTRATION BY EXTRACORPOREAL CIRCUITS}

There was initial enthusiasm for intermittently applied extracorporeal UF strategies following the EUPHORIA study (12). However, 2 randomized controlled trials (RCT) (UNLOAD and (ARRESS-HF) with a total of 388 patients were disappointing. UNLOAD showed greater weight loss in the UF group (5.0 \pm 3.1 vs $3.1 \pm 3.5 \mathrm{~kg} ; p=0.001)$, and fewer rehospitalizations $(0.22 \pm 0.54$ vs $0.46 \pm 0.76 ; p<0.05)$, but no difference in secondary endpoints including dyspnea scores, renal function, 6-minute walking tests, or mortality (13). The CARRESS-HF study showed that UF was inferior to a stepped drug-based algorithm in preserving renal function at 96 hours. Ultrafiltration was also associated with a higher rate of adverse events (renal failure, bleeding and catheter-related complications) with no significant differences in the composite rate of death or rehospitalization for $\mathrm{HF}$ ( $38 \%$ and $35 \%$, respectively; $p=n s)$ (14). In a further retrospective review of a group of decompensated patients with $\mathrm{HF}$ offered slow continuous ultrafiltration (SCUF), despite improved hemodynamics, there was a high in-hospital mortality and dialysis dependence rate (15). One can either conclude, then, that the rate of fluid removal may not be the issue (which may be similar to that obtained with PD), or that there may be a problem of extracorporeal blood therapies in general. Whatever the reason, extracorporeal blood circulating therapies have been largely abandoned for widespread or long-term use, and this may have contributed to the relative lack of interest from cardiologists.

\section{ULTRAFILTRATION ACHIEVED FROM PD}

Evidence that PD may be good for HF has existed for a long time (10), with amelioration of electrolyte abnormalities, improvements in fluid status and restoration of diuretic responsiveness (16). In contrast to extracorporeal treatment, PD achieves UF more slowly and cheaply and is largely performed at home. Peritoneal dialysis regimens prescribed for $\mathrm{HF}$ alone may be less onerous than those for renal failure regimes for dialysis, in that many use fewer exchanges (often 1 or 2), aimed predominantly at UF, without the pressing need to consider other solute removal targets. In centers with expertise, a PD catheter can be inserted under local anesthesia (LA) and be used immediately, but general anesthesia and pneumoperitoneum for laparoscopic insertion in these cardiovascularly unstable patients can often be achieved without major problems (17). Most, if not all, such patients have some antiplatelet therapy in their medication list, and in our experience anticoagulation and antiplatelet therapy may not need to be stopped completely because we use a relatively avascular midline approach to PD insertion with LA. Further we have inserted catheters in patients with surgical abdominal scars, on the grounds that careful LA placement, if it proceeds without complication, may be less risky than formal laparotomy or laparoscopy. Patients with hernias have also been successfully dialyzed overnight without the need for formal hernia repair. It is therefore clear that PD may be offered as a selective therapy to improve fluid status and symptoms in HF patients with CKD, with few complications like peritonitis or catheter dysfunction (18).

\section{BENEFITS OF PD OVER DIURETICS}

The benefits of PD compared to diuretics may be related to the relative lack of neurohumoral activation. Specifically, PD does not seem to activate the sympathetic nervous system, renin-angiotensin-aldosterone, endothelin, and vasopressin systems often seen after intravascular volume depletion seen with diuretics (19), and may even result in better preservation of residual renal function (20). There is also speculation that other harmful mediators may also be removed (including urate, atrial natriuretic peptide, tumor necrosis factor [TNF]-alpha, monocyte chemoattractant protein [MCP]-1 and interleukin 6 [IL-6], and a so-called myocardial depressant factor) (21).

In patients with no overt need for renal replacement therapy, a single daily peritoneal exchange with icodextrin has been shown to be efficacious to achieve the required fluid removal (22). This approach is also very conducive to home-based treatment and offers obvious lifestyle and economic advantages over extracorporeal treatments performed in hospitals or clinics. The optimal prescription and resultant UF from PD for a patient with HF and CKD will be dependent on a number of factors, including patient's peritoneal membrane permeability, type of PD (continuous ambulatory PD [CAPD] or automated PD [APD]) and choice of osmotic agent, total volume and duration of dwell. However, we often start with a single $(1.5-2 \mathrm{~L})$ long $(8-10 \mathrm{hr})$ dwell of icodextrin with the aim of achieving an additional $200-400 \mathrm{~mL}$ of ultrafiltrate and consequent removal of an extra $20-50 \mathrm{mmol}$ of sodium. Hyponatremia is a common observation with prognostic 
implications in cardiac failure $(23,24)$ and some studies have set out to remove free water with drugs (e.g. tolvaptan). These have shown that this strategy is achievable but does not have effects on overall mortality (25). The same effect could be achieved with glucose-based exchanges with free water being cleared early through aquaporin 1 channels (26), although the utility of using this as a clinical goal is uncertain.

\section{OUTCOMES OF PD PATIENTS IN HEART FAILURE}

\section{HOSPITALIZATIONS}

The reduction in hospital stays is a key metric by which to judge the success of any PD regime for $\mathrm{HF}$, not least because the reduced costs of hospital admissions are likely to be the key economic driver to encourage use of this therapy. Many, if not most, studies have addressed this issue, usually by retrospective comparison to previous admission days, and shown marked reduction in presentations and hospital bed days after institution of therapy (27-29). A crude figure for the reduction in admissions has been estimated to be $\sim 83 \%$ (30) which, if proven in RCTs would almost certainly add substantial economic weight to the proponents of this therapy.

\section{SURVIVAL}

Because of the retrospective or cohort nature of many of these studies, it has been impossible to determine whether PD increases the quantity of life. Most comparators are with historical controls or compared to the (short) life expectancy of patients with severe HF in other trials, e.g. CONSENSUS-1 where mortality of New York Heart Association (NYHA) IV patients was $26 \%$ in the enalapril-treated group and $44 \%$ in the controls at 6 months (31). Although variable, some studies show remarkable survival benefits of PD-treated patients with rates as high as $85 \%$ at 1 year (27). When one considers the age and natural life expectancy of this group, this sort of survival is comparable to patients in the SAVE trial with reduced left ventricular ejection fractions (LVEF $35-40 \%$ ) but with no or mild symptoms (NYHA Class I \& II).

Against this is the issue of how much useful functional improvement is gained. In one study only around a third of patients regained full functional independence (32), which means that the rest either died or remained dependent to a certain extent, and this is likely to be important information when weighing the risks and benefits of such therapy. The difficulty as ever comes with the heterogeneity of case mix and the non-randomized nature of all the studies. However, it can be appreciated how difficult it is to design and run such a trial to test the hypothesis with an adequate control group, and to date this has proved impossible.

\section{CARDIAC IMPROVEMENT}

If one accepts that PD does improve symptoms, questions arise as to whether this is really due to an improvement in cardiac muscle function or maybe merely improves tissue and (especially) pulmonary congestion. A number of studies have addressed this issue by examining the effects on the heart with echocardiography. Improvements have been demonstrated in various parameters of cardiac function including LVEF (29), with icodextrin in particular showing a favorable effect on hemodynamics and left ventricular end-diastolic diameter (LVEDD) (28). There are no published data on patients with predominantly right heart failure, which often causes resistant ascites and hepatic dysfunction. In our experience some patients benefit greatly from PD in this situation, often with marked improvements in symptoms and liver function tests, although blood pressure usually remains very low.

\section{SYMPTOMS AND QUALITY OF LIFE}

Almost all studies report symptomatic improvement and a reduction in NYHA grading in survivors $(19,28)$. Some studies have also favorably assessed the quality-of-life improvements using scoring tools like the Minnesota Living with Heart Failure Questionnaire (33).

\section{HEART FAILURE PD PRESCRIPTIONS}

Sodium removal is key to success for most $\mathrm{HF}$ regimes and these are best facilitated by chronic CAPD rather than APD with glucose-based solutions, because sodium removal is hindered by early sodium sieving and short dwell times in APD (34). In APD, this effect is almost completely abrogated by the use of icodextrin which does not cause sodium sieving because it achieves UF mainly via small pores and not aquaporin channels with UF maintained long into the dwell cycle. Thus, a number of studies have made use of icodextrin in HF prescriptions (27), sometimes exceeding the licensed maximum doses (up to 4/L/ day) with no apparent adverse events (35). Whilst some studies have suggested a high number of technical complications of this therapy (35), this is not our experience, and the incidence of peritonitis and catheter dysfunction in treating patients with HF appears no different to that of the general PD population.

\section{LACK OF RCT TRIAL EVIDENCE}

Many renal physicians are convinced that PD is an excellent therapy for HF, and indeed the German Society of Nephrology feel PD should be the treatment of choice for such patients (36) and have set up a registry for patients treated in this way (http://www.herz-niere.de). However while a number of RCTs have been proposed (30), none as yet have been completed or reported, and the total number of patients in the literature remains relatively low. Thus, some argue that this is merely a 'Hawthorn effect' and that purported benefits of PD may simply reflect the ongoing and usually exceptional care of the PD team in addition to perhaps an interested research team. In this context, 2 registry studies exist suggesting that hemodialysis (HD) may be a superior dialysis modality for patients with renal failure and co-existing HF. A large study from the US (1) showed 
worse survival of patients with $\mathrm{HF}$ at the start of dialysis on PD compared to $\mathrm{HD}$ with a relative risk of 1.3 (confidence interval [CI] 1.2 - 1.41), another French prospective observational study comparing a similar group and propensity scoring them also found better survival on $\mathrm{HD}$, with an adjusted hazard ratio of 1.5 (CI 1.3 - 1.7) (37). However, in these large registry studies selection bias cannot be controlled for, nor can we know the UF prescribed or achieved, and there is no data on the osmotic agent used as early studies using mainly glucose-based regimes are likely to have been a lot less successful than those using icodextrin. Nevertheless, the difficultly in designing and obtaining funding for prospective randomized studies to prove efficacy is evident when one starts to consider the difficulties of randomization, a control group and sample size, and many of us have given up trying to get such a study funded. Perhaps the best we can do is to continue to demonstrate improvements in functional status and cost savings with respect to conventional $\mathrm{HF}$ therapies, and in particular for that group requiring frequent hospitalizations. Small studies exist in this regard demonstrating cost effectiveness of this technique, for example Sánchez et al. showed an 11,000 euro saving with PD compared with conventional therapies (38). We do need to try to mobilize support from our cardiological colleagues if we are to make headway.

\section{PATIENT SELECTION}

One of the key and enduring facets of ensuring successful outcomes is picking the correct patients at the right moment in their natural history. The higher mental function, strength, and dexterity required to learn and perform the technique of PD and practice it successfully is often the only selection criterion on which to offer treatment, as this is the major player in determining outcomes. These are uniformly poor if therapy is instituted in an obtunded or demented patient without social support. Even when there is a good support network at home, the burdens imposed upon carers is often unbearable, and treatment failures are high if the patient is not fully engaged in the therapy. The ongoing challenge we face, and one in which we have singularly failed over the last 60 years or so, is to design studies to prove efficacy, and more closely define the parameters which portend success with this therapy. Nevertheless, treatments such as PD should be offered in parallel to good conservative care pathways for those patients in whom therapy has failed or for those in whom even low-exchange PD would be too burdensome.

\section{CONCLUSION}

Elderly patients suffer disproportionately from $\mathrm{HF}$, and despite improved management, HF is associated with significant morbidity, mortality and treatment cost. Management of HF in those who are treatment-resistant or intolerant of conventional therapies may include PD as an adjunctive therapy. Peritoneal dialysis is cheaper, gentle, and may offer greater independence than extracorporeal therapies, especially if using icodextrin as part of the prescription. Cost effectiveness is likely to be predicated upon proving a reduction in hospital stay, but a more forceful case could be made with more robust evidence from future trials that better define the patient population that would benefit the most from this modality, with the clear objectives of restoring functional independence and reducing readmission rates (and therefore cost). We are optimistic that PD has a place in the therapeutic armamentarium in treatment of patients with HF. We just need to keep developing the evidence to produce a cogent strategy with a larger evidence base on which to advocate its use.

\section{KEY POINTS}

- Heart failure is an important and expensive issue in the elderly and frequently co-exists with renal impairment.

- Ultrafiltration therapies represent a potentially useful adjunctive treatment for patients with severe heart failure associated with frequent hospital admissions.

- Trials of extracorporeal UF therapies have failed to fulfil their early promise in treatment of diuretic-resistant heart failure.

- Peritoneal dialysis is a gentle and relatively cheap UF therapy that may reduce hospitalization, cost of treatment and may improve quality of life and survival in patients with severe heart failure who are frequently admitted to hospital.

- Patient selection and cardiological support is key to successful use of PD in heart failure.

\section{DISCLOSURES}

SGH has received research funding and honoraria and served on advisory boards for Baxter.

\section{REFERENCES}

1. Stack AG, Molony DA, Rahman NS, Dosekun A, Murthy B. Impact of dialysis modality on survival of new ESRD patients with congestive heart failure in the United States. Kidney Int 2003; 64:1071-9.

2. Vinson JM, Rich MW, Sperry JC, Shah AS, McNamara T. Early readmission of elderly patients with congestive heart failure. J Am Geriatr Soc 1990; 38:1290-5.

3. Chen J, Normand SL, Wang Y, Krumholz HM. National and regional trends in heart failure hospitalization and mortality rates for medicare beneficiaries, 1998-2008. JAMA 2011; 306:1669-78.

4. Members WG, Lloyd-Jones D, Adams RJ, Brown TM, Carnethon M, Dai S, et al. Heart disease and stroke statistics-2010 update: a report from the American Heart Association. Circ 2010; 121(7):e46-215.

5. Conway B, Webster A, Ramsay G, Morgan N, Neary J, Whitworth C, etal. Predicting mortality and uptake of renal replacement therapy in patients with stage 4 chronic kidney disease. Nephrol Dial Transplant 2009; 24:1930-7.

6. Tomlinson L, Holt SG. Is the kidney just a modified blood vessel? Unravelling the direction of causality between cardiovascular and renal disease. Atherosclerosis 2011; 216:275-6.

7. Davenport A, Anker SD, Mebazaa A, Palazzuoli A, Vescovo G, Bellomo R, et al. ADQI 7: the clinical management of the cardio-renal syndromes: work group statements from the 7th ADQI consensus conference. Nephrol Dial Transplant 2010; 25:2077-89.

8. Yancy CW, Jessup M, Bozkurt B, Butler J, Casey DE, Drazner MH, et al. 2013 ACCF/AHA guideline for the management of heart failure: a report of the American College of Cardiology Foundation/American Heart Association 
Task Force on Practice Guidelines. Circ 2013; 128(16):e240-327.

9. Adler ED, Goldfinger JZ, Kalman J, Park ME, Meier DE. Palliative care in the treatment of advanced heart failure. Circ 2009; 120(25):2597-606.

10. Schneierson SJ. Continuous peritoneal irrigation in the treatment of intractable edema of cardiac origin. Am J Med Sci 1949; 218:76-9.

11. Eshaghian S, Horwich TB, Fonarow GC. Relation of loop diuretic dose to mortality in advanced heart failure. Am J Cardiol 2006; 97:1759-64.

12. Costanzo MR, Saltzberg M, O'Sullivan J, Kotsos T. EUPHORIA trial: early ultrafiltration therapy in patients with decompensated heart failure and observed resistance to intervention with diuretic agents. J Card Fail 2004; 10:S78.

13. Costanzo MR, Guglin ME, Saltzberg MT, Jessup ML, Bart BA, TeerlinkJR, et al. Ultrafiltration versus intravenous diuretics for patients hospitalized for acute decompensated heart failure. J Am Coll Cardiol 2007; 49:675-83.

14. Bart B, Goldsmith SR, Lee KL, Givertz MM, O'Connor CM, Bull D, et al. Ultrafiltration in decompensated heart failure with cardiorenal syndrome. N Engl J Med 2012; 367:2296-304

15. Patarroyo M, Wehbe E, Hanna M, Taylor D0, Starling RC, Demirjian S, et al. Cardiorenal outcomes after slow continuous ultrafiltration therapy in refractory patients with advanced decompensated heart failure. J Am Coll Cardiol 2012; 60:1906-12.

16. Lu M, CD S, Onesti G, Heider C, Ramirez 0, An B. Peritoneal dialysis for refractory congestive heart failure. JAMA 1967; 199:873-8.

17. Bar-Zohar D, Sagie B, Lubezky N, Blum M, Klausner J, Abu-Abeid S. Laparoscopic implantation of the Tenckhoff catheter for the treatment of end-stage renal failure and congestive heart failure: experience with the pelvic fixation technique. Isr Med Assoc J 2006; 8:174-8.

18. Koch M, Haastert B, Kohnle M, Rump LC, Kelm M, Trapp R, et al. Peritoneal dialysis relieves clinical symptoms and is well tolerated in patients with refractory heart failure and chronic kidney disease. EurJ Heart Fail 2012; 14(5):530-9.

19. Ellison DH. Diuretic therapy and resistance in congestive heart failure. Cardiology 2001; 96:132-43.

20. Nakayama M, Nakano H, Nakayama M. Novel therapeutic option for refractory heart failure in elderly patients with chronic kidney disease by incremental peritoneal dialysis. J Cardiol 2010; 55:49-54.

21. Ross EA, Kazory A. Ultrafiltration therapy for cardiorenal syndrome: physiologic basis and contemporary options. Blood Purif 2012; 34:149-57.

22. Basile C, Chimienti D, Bruno A, Cocola S, Libutti P, Teutonico A, et al. Efficacy of peritoneal dialysis with icodextrin in the long-term treatment of refractory congestive heart failure. Perit Dial Int 2009; 29:116-8.

23. Bettari L, Fiuzat M, Felker GM, $0^{\prime}$ Connor CM. Significance of hyponatremia in heart failure. Heart Fail Rev 2012; 17:17-26.

24. Bavishi C, Ather S, Bambhroliya A, Jneid H, Virani SS, Bozkurt B, et al. Prognostic significance of hyponatremia among ambulatory patients with heart failure and preserved and reduced ejection fractions. Am J Cardiol
2014; 113:1834-8.

25. Konstam MA, Gheorghiade M, Burnett JC, Grinfeld L, Maggioni AP, Swedberg $\mathrm{K}$, et al. Effects of oral tolvaptan in patients hospitalized for worsening heart failure: the EVEREST Outcome Trial. JAMA 2007; 297:1319-31.

26. Devuyst 0, Rippe B. Water transport across the peritoneal membrane. Kidney Int 2014; 85:750-8.

27. Bertoli SV, Musetti C, Ciurlino D, Basile C, Galli E, Gambaro G, et al. Peritoneal ultrafiltration in refractory heart failure: a cohort study. Perit Dial Int 2014; 34:64-70.

28. Paniagua R, Orihuela 0, Ventura M-J, Ávila-Díaz M, Cisneros A, VicentéMartínez $M$, et al. Echocardiographic, electrocardiographic and blood pressure changes induced by icodextrin solution in diabetic patients on peritoneal dialysis. Kidney Int Suppl 2008; 73:S125-30.

29. Courivaud C, Kazory A, Crépin T, Azar R, Bresson-Vautrin C, Chalopin J-M, et al. Peritoneal dialysis reduces the number of hospitalization days in heart failure patients refractory to diuretics. Perit Dial Int 2014;34:100-8.

30. Davies S, Lally F, Satchithananda D, Kadam U, Roffe C. Extending the role of peritoneal dialysis: can we win hearts and minds? Nephrol Dial Transplant 2014; 29(9):1648-54.

31. The CONSENSUS Trial Study Group. Effects of enalapril on mortality in severe congestive heart failure. Results of the Cooperative North Scandinavian Enalapril Survival Study (CONSENSUS). N Engl J Med 1987; 316:1429-35.

32. Sotirakopoulos NG, Kalogiannidou IM, Tersi ME, Mavromatidis KS. Peritoneal dialysis for patients suffering from severe heart failure. Clin Nephrol 2011; 76:124-9.

33. Núñez J, González M, Miñana G, Garcia-Ramón R, Sanchis J, Bodí V, et al. Continuous ambulatory peritoneal dialysis and clinical outcomes in patients with refractory congestive heart failure. Rev Esp Cardiol (Engl Ed) 2012; 65:986-95.

34. Struijk DG. Volume status in CAPD and APD: does treatment modality matter and is more always better? Perit Dial Int 2007; 27:641-4.

35. Cnossen $\Pi$, Kooman JP, Krepel HP, Konings CJAM, Uszko-Lencer NHMK, Leunissen KML, et al. Prospective study on clinical effects of renal replacement therapy in treatment-resistant congestive heart failure. Nephrol Dial Transplant 2012; 27(7):2794-9.

36. Schwenger $V$, Remppis AB. Renal replacement therapy for refractory heart failure. Internist (Berl) 2012; 53:823-32.

37. Sens F, Labeeuw M, Colin C, Villar E, Schott-Pethelaz A-M. Survival advantage of hemodialysis relative to peritoneal dialysis in patients with end-stage renal disease and congestive heart failure. Kidney Int 2011; 80:970-7.

38. SánchezJE, Ortega T, Rodríguez C, Díaz-Molina B, Martín M, Garcia-Cueto $\mathrm{C}$, et al. Efficacy of peritoneal ultrafiltration in the treatment of refractory congestive heart failure. Nephrol Dial Transplant 2010; 25:605-10. 